\title{
Does the Underground Sidewall Station Survey Method Meet MHSA Standards?
}

H. Grobler

Department of Mining Engineering and Mine Surveying, University of Johannesburg, South Africa, hgrobler@uj.ac.za

\section{http://dx.doi.org/10.4314/sajg.v5i2.6}

\begin{abstract}
The accuracy of all underground surveying is regulated by the standards described in the South African Mine Health and Safety Act. Four categories of accuracy is described. This paper describes the evaluation of accuracy standards of a typically configured sidewall station survey network in a narrow mine tunnel environment. The sidewall system lends itself to reduced risk exposure and greater efficiency coupled with added redundancy normally not found in standard underground networks. The question is asked whether or not this method of surveying will meet the MHSA standards of accuracy that was developed for typical hangingwall traverse type networks. Results obtained from a survey closure using a network of clusters of four sidewall stations demonstrates that under the described circumstances it will provide accuracies that are within the minimum standards of accuracy of a Class " $A$ " survey as prescribed by the Mine Health and Safety Act. It was found that a survey of the same network using clusters of only two sidewall stations method could not provide the same closure results over longer distances, but that this system lends itself well to Class " $C$ ” type surveys for reconnaissance and measuring purposes. Results indicated that the second method of surveying appears to have a greater probability of severe bearing error propagation over distances in excess of $180 \mathrm{~m}$ and would require regular check surveys in order to strengthen the network. Some of the advantages and disadvantages of the sidewall survey system are discussed to provide a better understanding of the application of this method of surveying on South African mines.
\end{abstract}

\section{Introduction}

The Mine Surveyor in South Africa operates in an environment strictly regulated by legislation and corporate Standards and Procedures. The preamble of the South African Mine Health and Safety Act, No. 29 of 1996 declares that the object of the Act is: "To provide for 
protection of the health and safety of employees and other persons at mines and, for that purpose to promote a culture of health and safety; ... " (Mine Health and Safety Act No 29 of 1996 Government Gazette 27 May 2011). Mine Surveyors therefore do not only have a moral obligation to ensure the accuracy of their work but also a legal responsibility to ensure the safety of mine employees as well as those of the community (Schofield W., 2007). The lives of mine workers depend directly on the accuracy of the survey network that controls the workings of the mine in which they work. Bannister stated that "understanding the minimum standards of accuracy that limit the accuracy of the measurement techniques is but one step to ensuring specifications are achieved" (Bannister A., 1998).

\section{MHSA Accuracy Standards}

The MHSA regulations make clear provision for the limits of accuracy to be expected from any survey. The minimum standards of accuracy prescribed by the Mine Health and Safety Act 17(14)(b) "the minimum standard of accuracy and class of survey for the fixing of survey stations on both horizontal and vertical planes are in accordance with the following formula:"

$$
A=0.015+\frac{s}{30000}
$$

"Where $s$ is the distance in metres between the known and the unknown survey station; provided that in the case of a traverse, after a check survey has been completed, the error in direction of a line between any two consecutive survey stations must not exceed 2 (two) minutes of arc, provided that the horizontal and vertical displacement between the measured position and final position of a survey station does not exceed 0,1 (zero comma one) metres; "'(Mine Health and Safety Act No 29 of 1996 Government Gazette 27 May 2011).

Chrzanowski defines three "orders" of survey networks as "control networks consist of first order loops which serve as basic control and are run in permanent mine workings, second order traverses run into headings and development areas, and third order stations used for detailed mapping of excavated areas and daily checks of mining progress in stopes and headings" (Chrzanowski, 1999). According to the MHSA, a Class "A" survey will be the standard of accuracy for a primary survey network used for fixing shaft positions, underground stations and underground connections (Mine Health and Safety Act No 29 of 1996 Government Gazette 27 May 2011). The accuracy of the normal network on an underground level of a mine can be 
defined as a secondary survey and classified as a Class " $\mathrm{B}$ " network, with the allowable accuracy calculated as follows:

$$
B=1.5 *\left[0.015+\frac{s}{30000}\right]
$$

The final category of survey network is a tertiary survey defined as survey networks that are extended into the production areas of a mine for measuring purposes and is defined as a Class "C" survey, with the following allowable error:

$$
C=3.0 *\left[0.015+\frac{s}{30000}\right]
$$

It is generally accepted in the South African mine survey industry that a "rule of thumb" of $20 \mathrm{~mm}$ should apply to all surveys. Bals remarked that this widely accepted rule of thumb probably came about as “... an adaptation of the Class A survey standard using a 60 metre steel tape: $0.015+(60 / 30000)$ gives $0.017 \mathrm{~m}$ or $20 \mathrm{~mm}$ for easy implementation. "(Bals, 2011 ).

\section{Test Phase}

The results of a closed loop traverse conducted in an underground tunnel at the University of Johannesburg, proved that the sidewall station method of surveying could meet the accuracy requirements of a Class " $\mathrm{A}$ ” type survey network. This change in traditional mine survey practice has enormous potential for underground surveying because of its contribution to "zeroharm" by removing the mine survey crew from a high risk area namely the hanging wall of deep level tunnels. Apart from the risk associated with vertical rock stresses it will also eliminate the risk of working at heights as well as moving the survey setup away from the high risk centre of the tunnel where machinery is bound to travel.

In order to evaluate the accuracy and efficiency of the survey method, it was decided to test a similar network in the workings of an active mine. The assumption was made that the survey method would meet the prescribed accuracy requirements and at the same time prove to be a safer and faster method of extending an underground development survey network. The sidewall station survey method ${ }^{1}$ would have to be properly evaluated to ascertain whether or not it can realistically be implemented on a working mine under production conditions. In order

\footnotetext{
${ }^{1}$ In this method a cluster of four pegs are installed in the wall of the excavation and the instrument is orientated by a resection or "Freestation"
} 
to evaluate the accuracy parameters obtained during this process it would be required to investigate the different classes of accuracy and the approved definition of each of these with reference to the types of network to which it applies. In total three case studies are discussed, investigating the methodology of network installation and then focussing on specific aspects of the network unique to each mine. A sidewall network was established in a deep level platinum mine in Rustenburg, an existing method used on a deep level goldmine on the Witwatersrand used for secondary networks and a network used in the main development of a copper mine in Phalaborwa was investigated as part of a check survey. For the purposes of the paper one of these case studies is discussed.

\section{Case Study on a Deep Level Platinum Mine}

The underground survey network in a deep level platinum mine in Rustenburg was establishing using a long baseline of $638.7 \mathrm{~m}$ in a straight section of an underground mine haulage ${ }^{2}$. The point of origin of the test baseline was surveyed using the conventional hangingwall method and the co-ordinates obtained from these observations were used to compare the accuracy of the freestation points. The hypothesis was made that if the freestation closure results was within the prescribed MHSA standards of accuracy, this method could be considered a viable alternative to the conventional hangingwall survey method.

In order to establish the first set of sidewall stations, a set of four wall stations were installed at a convenient distance from the instrument and co-ordinated using a single observation to determine distance and direction. The sidewall station positions were configured to be on the grade line and in pairs, within approximately $10 \mathrm{~m}$ of each other. This configuration replicates the standard grade-peg layout used to control the vertical positioning of a tunnel.

\subsection{Description of the Observation Methodology}

As with the sidewall station experiment at the University campus, survey stations were surveyed from the existing hangingwall control network. In order to check on the progress of the accuracy of the freestation method the target at the termination point (X17354) was observed from each consecutive freestation setup and compared to the conventional hangingwall traverse co-ordinates of the point X17354. Each freestation was indicated by a RS prefix in the observation file of the instrument. In this manner sidewall stations were installed from the new

\footnotetext{
${ }^{2}$ A tunnel developed at a slight gradient providing access to the orebody and used for the transfer of men and material as well as for the provision of ventilation, air, water and power
} 
freestation points up to a point where the last set of wall stations were installed around the foresight point X17354.

The time duration for peg installation during the initial phase of learning the method was 28 minutes on average for each setup. The speed of installation improved to 13 minutes once the crew had become familiar with the process and a manageable method of communication was agreed upon. The average duration of observation of points already installed averaged nine minutes. Time saving in the setting up of the instrument (levelling and centring), orientation, installation and observation of new sidewall stations was gained by not needing to use a ladder at the station, backsight and foresight positions.

\subsection{Method of Evaluating the Accuracy of the Sidewall Survey Stations}

In order to evaluate the accuracy of the sidewall stations, the final results of the last resection RS10 was compared with the co-ordinate of the foresight point X17354 obtained from the original survey. For the purpose of this evaluation, it was argued that the one long baseline would determine the final foresight point with greater accuracy than from a number of short traverses, which could introduce additional errors. At the final freestation setup, the instrument was set-up directly under the closure point and resurveyed by freestation.

\subsection{Sidewall Station Network Results}

The solution of final co-ordinates of the freestation position of the hangingwall survey station were calculated using the on-board resection software of the instrument ${ }^{3}$. The "freestation" software calculates the provisional co-ordinates, using each possible unique solution including the individual triangles, every combination of resection points and finally, a Helmert transformation. The results with the smallest number of observed minus calculated values are used to calculate the median of the values which in turn will provide the final result for the freestation position (Zimmerman, 1996).

The position of point RS10 was determined from the last set of sidewall stations installed around the hangingwall station X17354 for this purpose. A table of the original- and freestation co-ordinates are listed in Table 1. The term "estimated" indicates a point surveyed by freestation and the term "measured" indicates a point determined by traverse.

\footnotetext{
${ }^{3}$ The instrument used was a single-second total station with standard co-ordinate geometry and orientation functions.
} 
Table 1. Comparison of freestation co-ordinate closure

\begin{tabular}{|c|c|c|c|c|c|}
\hline Point & & Date stamp & Y Co-ord & X Co-ord & Elevation \\
\hline RS10 & Estimated & 04/16/2013 10:37:02 & -41567.7581 & 2842734.9140 & 843.3442 \\
\hline 17354 & Measured & 04/16/2013 08:55:54 & -41567.7640 & 2842734.9142 & 843.3787 \\
\hline & & Error & -0.0059 & 0.0002 & 0.0345 \\
\hline
\end{tabular}

\subsection{Closure Obtained at the Breakthrough Point}

The distance of tunnel surveyed, from peg X151915 to peg X17354, using the freestation method was determined to be $638.679 \mathrm{~m}$. Using the formula for minimum standards of accuracy required by the MHSA, the following parameters were calculated in Table 2.

Table 2. Calculated minimum standard of accuracy for the survey

\begin{tabular}{|l|c|c|c|} 
& & \multicolumn{3}{|c|}{ Class " A" $=0.015+\frac{s}{30000}$} \\
\hline MHSA Limit of Error & Distance & $\mathbf{6 3 8 . 6 7 9} \mathrm{m}$ & $\mathbf{1 2 7 7 . 3 6} \mathrm{m}$ \\
\hline Class A & "A" & $0.0363 \mathrm{~m}$ & $0.0576 \mathrm{~m}$ \\
\hline Class B & "A" * 1.5 & $0.0544 \mathrm{~m}$ & $0.0864 \mathrm{~m}$ \\
\hline Class C & "A" * 3.0 & $0.1089 \mathrm{~m}$ & $0.1727 \mathrm{~m}$ \\
\hline
\end{tabular}

The minimum standard of accuracy between the provisional and final co-ordinate of a survey station is defined as the vector distance calculated from the difference in the $\mathrm{Y}$ coordinate and the X co-ordinate, where "s" is the distance of the total traverse from the starting survey station to the "closure" survey station in the following manner:

Table 3. Error vector of freestation closure

\begin{tabular}{|c|c|c|c|c|c|}
\hline Point & & Date stamp & Y Co-ord & X Co-ord & Elevation \\
\hline RS10 & Estimated & 04/16/2013 10:37:02 & -41567.7581 & 2842734.9140 & 843.3442 \\
\hline \multirow[t]{4}{*}{17354} & Measured & $04 / 16 / 2013$ 08:55:54 & -41567.7640 & 2842734.9142 & 843.3787 \\
\hline & & Error & -0.0059 & 0.0002 & 0.0345 \\
\hline & & & Error Vector & $=\sqrt{\Delta y^{2}+\Delta x^{2}}$ & \\
\hline & & Error Vector & 0.006 & metres & \\
\hline
\end{tabular}

According to the minimum standard of accuracy, the obtained closure is deemed to be within the minimum standard of accuracy required for a Class " $\mathrm{A}$ " network. Based on the regulations, the haulage used in this project can be classified as a Class "B" secondary survey network, as the regulation states that: “... any survey carried out for the purpose of fixing main or access development, mine boundaries...”(Mine Health and Safety Act No 29 of 1996 Government Gazette 27 May 2011). As is the case on most South African mines, the mining property is adjacent to other mining properties. In such a case where the survey network in a 
haulage will be used for the determination of the position relative to a boundary and the establishment of connections, the standard of accuracy of the network should rather be upgraded to a Class "A".

During the test phase of the project it was found that the instrument software could not cope with the inverted instrument and target heights normally used in conventional hangingwall surveying. This problem was overcome by ignoring both the signs of the instrument and target heights in order to provide correct elevation results. The closure on elevation, although not as good as on the horizontal plane, was still within the prescribed minimum standards of accuracy. The bearing error calculated from a join between the original point and the resected point was compared to the baseline direction and listed in Table 4 .

Table 4. Bearing error comparison

\begin{tabular}{|c|c|}
\hline Bearing X15915 to X17354 & $359: 59: 04$ \\
\hline Bearing RS17 to RS10 (freestation of X17354) & $359: 59: 06$ \\
\hline Error & $0: 00: 02$ \\
\hline
\end{tabular}

It is standard practice on mines to check the direction of a survey network every 500 $1000 \mathrm{~m}$ using a gyroscope. The data obtained from this test indicates that with sufficient reference objects and careful observations, bearing error propagation can be controlled.

\subsection{The Two-point Freestation Method}

Upon completion of the four sidewall station method over a distance of $630 \mathrm{~m}$, the direction of the survey was reversed and a quick method using only two reference points as described in the Australian context (Jaroz \& Shepard, 2004) were used. The "Australian method" using only two reference points as described by Jarozand Shepard (Jaroz \& Shepard, 2004) was used to make a closure on the origin point of the hangingwall baseline. A comparison of the sidewall station co-ordinates surveyed initially and resurveyed using the two-point method was made. The results of the points resurveyed as well as the closure is listed in Table 5. From the results it can be seen that a Class " $\mathrm{A}$ " closure could be possible for distances up to $180 \mathrm{~m}$ before the accuracy starts deteriorating to a Class "C" type survey. 
South African Journal of Geomatics, Vol. 5. No. 2, September 2016

Table 5. Freestation co-ordinate comparison

Freestation using two points comparison of Sidewall station co-ordinates

\begin{tabular}{|c|c|c|c|c|c|c|c|c|c|c|c|}
\hline \multirow[b]{2}{*}{$\begin{array}{l}\text { Freestation } \\
\text { Point }\end{array}$} & \multirow[b]{2}{*}{ Point } & & \multirow[b]{2}{*}{ Date stamp } & \multirow[b]{2}{*}{ YCo-ord } & \multirow[b]{2}{*}{$x$ Co-ord } & \multirow[b]{2}{*}{ Elevation } & \multicolumn{5}{|c|}{ Minimum standard of accuracy for distance } \\
\hline & & & & & & & $\begin{array}{l}\text { Horizontal } \\
\text { Distance from } \\
\text { origin }\end{array}$ & Class "A" & Class "B" & Class "C" & CLASS? \\
\hline & RS17 & Estimated & 04/16/2013 11:37:52 & -41567.7230 & 2842096.2407 & 839.4191 & & & & & \\
\hline & X15915 & Control & 04/16/2013 08:43:49 & -41567.5900 & 2842096.2350 & 839.5640 & & & & & \\
\hline & & & Error & 0.1330 & -0.0057 & 0.1449 & & & & & \\
\hline \multirow{7}{*}{ RS17 } & WS01 & Measured & 04/16/2013 08:50:29 & -41568.6921 & 2842110.7119 & 841.4029 & & & & & \\
\hline & WS01A & Measured & 04/16/2013 11:25:30 & -41568.7961 & 2842110.7151 & 841.3375 & & & & & \\
\hline & & & Error & -0.1040 & 0.0032 & -0.0654 & & & & & \\
\hline & & & Error vector for RS17 & \multicolumn{2}{|c|}{-0.1074} & -0.0634 & 638.6735 & 0.036 & 0.054 & 0.109 & Class C \\
\hline & WSO2 & Measured & 04/16/2013 08:51:22 & -41566.4407 & 2842106.6790 & 841.3295 & & & & & \\
\hline & WS02A & Measured & 04/16/2013 11:24:37 & -41566.5548 & 2842106.6791 & 841.2681 & & & & & \\
\hline & & & Error & -0.1141 & 0.0001 & -0.0614 & & & & & \\
\hline \multirow{7}{*}{ RS16 } & WS05 & Measured & 04/16/2013 09:10:10 & -41568.8739 & 2842194.3530 & 841.4001 & & & & & \\
\hline & WS05A & Measured & 04/16/2013 11:16:46 & -41568.9118 & 2842194.3562 & 841.3373 & & & & & \\
\hline & & & Error & -0.0379 & 0.0032 & -0.0628 & & & & & \\
\hline & & & Error vector for RS16 & \multicolumn{2}{|c|}{-0.0253} & -0.0600 & 532.0328 & 0.033 & 0.049 & 0.098 & Class A \\
\hline & WS08 & Measured & 04/16/2013 09:11:34 & -41566.2546 & 2842212.3642 & 841.7081 & & & & & \\
\hline & W508A & Measured & 04/16/2013 11:16:04 & -41566.2713 & 2842212.3650 & 841.6508 & & & & & \\
\hline & & & Error & -0.0167 & 0.0008 & -0.0573 & & & & & \\
\hline \multirow{7}{*}{ RS15 } & WS10 & Measured & 04/16/2013 09:20:19 & -41566.3288 & 2842278.9485 & 842.0656 & & & & & \\
\hline & WS10A & Measured & 04/16/2013 11:09:47 & -41566.2915 & 2842278.9501 & 842.0207 & & & & & \\
\hline & & & Error & 0.0373 & 0.0016 & -0.0449 & & & & & \\
\hline & & & Error vector for RS15 & \multicolumn{2}{|c|}{0.0465} & -0.0456 & 445.7845 & 0.030 & 0.045 & 0.090 & Class C \\
\hline & WS11 & Measured & 04/16/2013 09:20:58 & -41568.6979 & 2842293.1933 & 842.2884 & & & & & \\
\hline & WS11A & Measured & 04/16/2013 11:09:13 & -41568.6462 & 2842293.1956 & 842.2421 & & & & & \\
\hline & & & Error & 0.0517 & 0.0023 & -0.0463 & & & & & \\
\hline \multirow{7}{*}{ RS14 } & WS13 & Measured & 04/16/2013 09:29:56 & -41568.7268 & 2842352.8036 & 842.3573 & & & & & \\
\hline & WS13A & Measured & 04/16/2013 11:01:48 & -41568.6547 & 2842352.8055 & 842.3152 & & & & & \\
\hline & & & Error & 0.0721 & 0.0019 & -0.0421 & & & & & \\
\hline & & & Error vector for RS14 & \multicolumn{2}{|c|}{0.0777} & -0.0367 & 371.6932 & 0.027 & 0.041 & 0.082 & Class C \\
\hline & WS16 & Measured & 04/16/2013 09:31:21 & -41566.4259 & 2842367.8200 & 842.2830 & & & & & \\
\hline & WS16A & Measured & 04/16/2013 11:02:37 & -41566.3459 & 2842367.8214 & 842.2518 & & & & & \\
\hline & & & Error & 0.0800 & 0.0014 & -0.0312 & & & & & \\
\hline \multirow{7}{*}{ RS13 } & WS18 & Measured & 04/16/2013 09:39:42 & -41566.6228 & 2842453.8097 & 843.0901 & & & & & \\
\hline & WS18A & Measured & 04/16/2013 10:55:08 & -41566.5684 & 2842453.8109 & 843.0659 & & & & & \\
\hline & & & Error & 0.0544 & 0.0012 & -0.0242 & & & & & \\
\hline & & & Error vector for RS13 & 0.0 & 491 & -0.0273 & 268.8476 & 0.024 & 0.036 & 0.072 & Class C \\
\hline & WS19 & Measured & 04/16/2013 09:40:12 & -41568.8263 & 2842474.5296 & 843.2152 & & & & & \\
\hline & WS19A & Measured & 04/16/2013 10:54:31 & -41568.7830 & 2842474.5290 & 843.1848 & & & & & \\
\hline & & & Error & 0.0433 & -0.0006 & -0.0304 & & & & & \\
\hline & WS21 & Measured & 04/16/2013 09:55:11 & -41568.9807 & 2842552.2498 & 843.3563 & & & & & \\
\hline & WS21A & Measured & 04/16/2013 10:48:30 & -41568.9736 & 2842552.2503 & 843.3273 & & & & & \\
\hline & & & Error & 0.0071 & 0.0005 & -0.0290 & & & & & \\
\hline RS12 & & & Error vector for RS12 & 0.0 & 033 & -0.0250 & 180.2048 & 0.021 & 0.032 & 0.063 & Class A \\
\hline & WS24 & Measured & 04/16/2013 09:57:14 & -41566.5372 & 2842562.0668 & 843.7462 & & & & & \\
\hline & WS24A & Measured & 04/16/2013 10:49:11 & -41566.5376 & 2842562.0663 & 843.7252 & & & & & \\
\hline & & & Error & -0.0004 & -0.0005 & -0.0210 & & & & & \\
\hline & WS26 & Measured & 04/16/2013 10:07:47 & -41566.4399 & 2842650.2476 & 843.8407 & & & & & \\
\hline & WS26A & Measured & 04/16/2013 10:42:28 & -41566.4296 & 2842650.2475 & 843.8288 & & & & & \\
\hline & & & Error & 0.0103 & -0.0001 & -0.0119 & & & & & \\
\hline RS11 & & & \begin{tabular}{|l|l} 
Error vector for RS11 \\
\end{tabular} & 0.0 & 087 & -0.0095 & 74.8708 & 0.017 & 0.026 & 0.052 & Class A \\
\hline & WS27 & Measured & 04/16/2013 10:08:17 & -41569.0765 & 2842664.0714 & 844.4251 & & & & & \\
\hline & WS27A & Measured & 04/16/2013 10:41:35 & -41569.0681 & 2842664.0701 & 844.4180 & & & & & \\
\hline & & & Error & 0.0084 & -0.0013 & -0.0071 & & & & & \\
\hline
\end{tabular}




\subsection{A Comparison Between the Two Methods}

The bearing error calculated from a join between the RS10 the freestation point located at the position of survey station X17354, and the last resected point located at X15915, was compared to the baseline direction and listed in Table 6 .

Table 6. Closure error

\begin{tabular}{|r|r|r|r|r|}
\hline Bearing RS17 to RS10 & $359: 59: 49$ & Horizontal Distance RS17 to RS10 & 638.673 & $\mathrm{~m}$ \\
\hline Bearing X15915 to 17354 & $359: 59: 04$ & torizontal Distance X15915 to 17354 & 638.679 & $\mathrm{~m}$ \\
\hline Bearing Error & $00: 00: 45$ & & -0.006 & $\mathrm{~m}$ \\
\hline
\end{tabular}

The MHSA states that an error of 2 minutes of arc between consecutive stations is required after a check survey has been completed. Using the bearing error and distance between the two points, a closure error of $0.139 \mathrm{~m}$ could be expected over the distance. This expected closure distance compares well to the 0.109 calculated error vector obtained from the observations and provides evidence that the error propagation in bearing has a larger impact during sidewall station surveying. The final closure of the two-point survey method was found not to be within the prescribed minimum standard of accuracy. Due to the North-South orientation of the tunnel, it seems that the error in bearing increased far more rapidly than the error in distance. It is suggested that the error propagation of the survey is as a result of the increased distance as well as the reduced number of observed points. For a distance less than $180 \mathrm{~m}$, the two-point method of surveying will meet the accuracy of a Class " $A$ " survey after which the accuracy deteriorates rapidly. The method is sufficient for "working" surveys used to establish control in a tunnel and volumetric determinations, but such a network will need to be strengthened by additional control points and observations during follow-up surveys before it would be acceptable for use as a primary network. Table 7 compares the bearing and horizontal distance results obtained from the two methods:

Table 7. A comparison of relative accuracies obtained

\begin{tabular}{|c|c|c|c|c|}
\hline \multicolumn{5}{|c|}{ Comparison of relative closure accuracies between the two methods. } \\
\hline \multirow{2}{*}{\multicolumn{5}{|c|}{ Four sidewall stations }} \\
\hline & & & & \\
\hline Bearing X15915 to X17354 & 359:59:04 & Horiz.Dist. from X15915 to X17354 & 638.67922 & \\
\hline Bearing X15915 to RS10(X17354) & 359:59:06 & Horiz.Dist. from X15915 to RS10(X17354) & 638.67902 & \\
\hline Error in bearing closure & 0:00:02 & Error in HD closure & 0.00020 & $m$ \\
\hline & & & & \\
\hline \multicolumn{5}{|c|}{ Two sidewall stations } \\
\hline Bearing X15915 to X17354 & 359:59:04 & Horiz.Dist. from X15915 to X17354 & 638.67922 & \\
\hline Bearing RS10(X17354) toRS17 X15915 & 359:59:49 & Horiz.Dist. from RS10(X17354) toRS17 X15915 & 638.673301 & \\
\hline Error in bearing closure & $0: 00: 45$ & Error in HD closure & 0.00592 & \\
\hline
\end{tabular}




\section{Advantages of the Sidewall Station Method}

The freestation method of surveying requires no measurements of instrument-or target heights as a zero constant is used. This prevents a number of observation errors commonly encountered during conventional traversing. The use of four instead of one reference object increases redundancy in the observations made. Combinations of reference points can be used in order to improve the robustness of the network. The freestation method removes any error introduced by centring under a hangingwall station that can be introduced by high ventilation flow and operator error. The sidewall station reduces the risk of exposure to working at heights and being in contact with the hangingwall of the excavation. This makes the need for elevating equipment redundant and has the benefit of increasing the speed of set-up and peg installation, while at the same time providing more options for peg placement and instrument positioning.

\section{Disadvantages of the Sidewall Station Method}

Any error in freestation positions will be transferred and perpetuated by the installation of new sidewall stations installed from this setup and lead to error propagation. Incorrect identification of points may still provide a "fix" but will be incorrect. Should the surveyor incorrectly sighting or measure points that are in the same line of sight an incorrect fix may be obtained.

\section{Suggestions and Recommendations for Using the Sidewall Station Method}

Most of the disadvantages mentioned can be overcome if the instrument used is equipped with automatic target recognition (ATR) software. It is strongly recommended that the freestation software used must include the allowance for face left and face right readings combined with measuring the distance in each face. The correct numbering and identification of pegs are crucial to this method of surveying, it would therefore be advised that the surveyor personally oversees the installation and numbering process. The use of a skilled survey crew is essential to the success of this method of surveying.

When using the sidewall station method it is recommended that the maximum distance before a check survey is completed should be around $750 \mathrm{~m}$, when bearing checks by gyroscope must be made in order to prevent bearing error propagation. In addition closures between networks on different levels or sections should be made wherever possible.

The use of the correct prism constant must be rigorously enforced and any new prisms should be verified before being used in the network. At the same time it is critical that the 
survey crew understands that the co-ordinates of sidewall stations are "pseudo" positions dictated by the size of the prism and the offset of the prism centre which is at an offset from the true sidewall position, rather than the position of the survey plug itself. That implies that any changes to the survey "hardware" including prisms, stems and attachment points must be carefully considered before implementing.

\section{Conclusion}

From the results obtained in this "real-world" study in can be concluded that the sidewall station method used for the establishment of a primary survey network is plausible under certain circumstances. All three case studies provided proof that the sidewall station method can provide good comparative results with the conventional hangingwall survey method. It is clear that certain parameters of geometry and observation protocol must be adhered to in order to obtain accuracies that will meet the prescribed minimum standards of accuracies for a Class "A" survey. It has been found that the method provides a saving in time and offers a reduced risk exposure profile to the survey crews. Although time and safety considerations may be considered as trivial, the impact of these findings on the safety and efficiency on the mine surveyor is of significant importance. It follows that the four-point sidewall survey station provides more accurate results with less error propagation than the results obtained from a twopoint setup method and can therefore provide a safe and accurate alternative to conventional mine surveying techniques.

\section{References}

Bals, A. [. (2011 , March 18 01:50 PM). e-mail communication RE: PhD research information. (H. Grobler, Interviewer)

Bannister A., R. S. (1998). Surveying 7th Edition. Pearson Education Limited, ISBN 0-58230249-8.

Chrzanowski, A. (1999). Chapter 16. Engineering and Mining surveys, pages 492 to 527. In Mapping a Northern Land (ISBN 0-7735-1689-1 ed.). MCGrath G., Sebert L.M.

Jaroz, A., \& Shepard, L. (2004). Recent changes in Underground traversing techniques in Western Australia.

Mine Health and Safety Act No 29 of 1996 Government Gazette 27 May 2011. (n.d.).

Roos, C. (2013, April). Survey procedures in the underground environment.

Schofield W., B. M. (2007). Engineering Surveying, Sixth Edition. Elesevier, Butterworth Heineman, ISBN 13 978-0-7506-6949-8.

Zimmerman, M. (1996). Free Station (v2.1) FS01_v21 DOC 15/05/96. Leica Geosystems. 